\title{
Asymmetric septal hypertrophy and hypothyroidism in children
}

\author{
DENNIS I ALTMAN, JILL MURRAY, SELWYN MILNER, RAY DANSKY, \\ SOLOMON E LEVIN
}

\begin{abstract}
From the Department of Paediatrics, Baragwanath and Fohannesburg Hospitals, and School of Pathology, Department of Pathology (Anatomical), South African Institute for Medical Research and University of the Witwatersrand, fohannesburg, South Africa
\end{abstract}

SUMMARY Any echocardiographic study of two children with hypothyroidism demonstrated the presence of asymmetric septal hypertrophy. One child died aged 11 months, and pronounced thickening of the interventricular septum was confirmed at necropsy. There was also hypertrophy of the left ventricular free wall. Histological examination showed only slight muscle fibre disarray, but there was striking vacuolation and hypertrophy of muscle fibres. In the second case, a child aged five years, the asymmetric septal hypertrophy disappeared after 18 months' treatment with L-thyroxine. Furthermore, other indices of myocardial function also returned to normal. The mechanism producing asymmetric septal hypertrophy in hypothyroidism is unknown. These are the youngest cases in which this association has been reported.

Pericardial effusions and pronounced abnormalities in left ventricular function have been demonstrated in hypothyroid adults by echocardiography. ${ }^{12}$ Furthermore, Santos et al have described patterns of asymmetric thickening or hypertrophy of the interventricular septum and other features compatible with hypertrophic obstructive cardiomyopathy in adults with long standing hypothyroidism. ${ }^{3}$ These abnormalities were reversed after treatment with thyroid hormone. In the first reported echocardiographic study of 15 hypothyroid children, Hayford et al found no appreciable abnormality in cardiac chamber or myocardial dimensions, systolic time intervals, or indices of myocardial contractility compared with a normal population. ${ }^{4}$ Both Nose et al and Farooki et al, however, found prolonged systolic time intervals in children with primary hypothyroidism, and these indices became normal with treatment. ${ }^{56}$ Finally, in a recent study of 12 babies with congenital hypothyroidism, left ventricular systolic and diastolic dimensions, posterior wall

Requests for reprints to Professor Solomon E Levin, Department of Paediatrics, Medical School, York Road, Parktown, Johannesburg 2193, South Africa.

Accepted for publication 2 May 1985 thickness, and end diastolic and systolic volumes were all lower than normal. ${ }^{7}$

We describe two children with hypothyroidism who had echocardiographic features of asymmetric septal hypertrophy. As far as we are aware they are the youngest patients in whom this abnormality has been reported. Asymmetric septal hypertrophy was confirmed at necropsy in one infant. In the surviving patient the abnormality had disappeared 18 months after the start of thyroid treatment.

\section{Case reports}

\section{CASE 1}

An 11 month old female infant (weight $5.6 \mathrm{~kg}$, length $60 \mathrm{~cm}$, below 3rd percentile) was admitted to hospital because of constipation, lethargy, and poor feeding. She was the second child of normal unrelated parents and had been delivered vaginally at another hospital after an uneventful pregnancy. She had all the clinical features of severe myxoedema including a large tongue, distended abdomen, and dry scaly skin. She cried poorly, had never smiled, and had never attempted to sit. The heart rate was 88 beats per minute and all the pulses were palpable. On auscultation of the heart, a grade 2/6 high-pitched ejection systolic murmur was heard loudest at the third and fourth left intercostal spaces. The liver edge was 
Table 1 Thyroid function studies

\begin{tabular}{|c|c|c|c|c|}
\hline & \multirow[t]{2}{*}{ Case 1} & \multicolumn{2}{|l|}{ Case 2} & \multirow[b]{2}{*}{$\begin{array}{l}\text { Normal } \\
\text { values }\end{array}$} \\
\hline & & $\begin{array}{l}\text { Before } \\
\text { treatment }\end{array}$ & $\begin{array}{l}\text { After } 3 \text { months } \\
\text { of } L \text {-thyroxine }\end{array}$ & \\
\hline $\begin{array}{l}\text { Triiodothyronine uptake }(\%) \\
\text { Total thyroxine (nmol/1) } \\
\text { T7 index } \\
\text { Free thyroxine index } \\
\text { Total triiodothyronine (nmol/l) } \\
\text { Free thyroxine (pmol/l) }\end{array}$ & $\begin{array}{r}26 \\
14 \\
4 \\
1\end{array}$ & $\begin{array}{l}22 \\
19 \\
0 \cdot 33 \\
0 \cdot 2\end{array}$ & $\begin{array}{r}1 \cdot 6 \\
22 \cdot 2\end{array}$ & $\begin{array}{l}30-40 \\
60-150 \\
17-60 \\
5-12 \\
0 \cdot 8-3 \cdot 5 \\
10-25\end{array}$ \\
\hline $\begin{array}{l}\text { Thyroid stimulating hormone } \\
(\mu \mathrm{IU} / \mathrm{ml})\end{array}$ & $70 \cdot 5$ & $44 \cdot 8$ & 2.9 & $1 \cdot 5-8$ \\
\hline
\end{tabular}

palpable $4 \mathrm{~cm}$ below the right costal margin. The lungs were clinically normal. The haemoglobin concentration was $8 \cdot 1 \mathrm{~g} / \mathrm{dl}$.

Bone age was appreciably less than normal with no epiphyses in the humeral heads or the carpal bones. A chest $x$ ray examination showed a cardiothoracic ratio of 0.6 in a hyperinflated chest. The vascularity of the lungs was normal. The electrocardiogram showed a mean frontal QRS axis of $+90^{\circ}$ and voltages were generally low. A positive "mosque" sign ${ }^{8}$ was present in the right precordial leads (rounded symmetrical T waves), while the left precordial leads showed inverted $T$ waves. Thyroid function tests (Table 1) confirmed the diagnosis of hypothyroidism.

The $M$ mode echocardiogram showed asymmetric hypertrophy of the interventricular septum with a ventricular septal left ventricular posterior wall ratio of 2:1, and a septal thickness of $10 \mathrm{~mm}$ (Table 2). Systolic anterior motion of the mitral valve was seen. There was also evidence of a pericardial effusion (Fig. 1). Aortic valve motion was normal.

L-thyroxine $(0.025 \mathrm{mg}$ daily) was started on the day after admission. Nasogastric tube feeds were started. She collapsed suddenly 24 hours later and had a cardiorespiratory arrest. Resuscitation was unsuccessful.

Necropsy findings A small fibrosed thyroid gland was present in the usual position. Microscopically this gland consisted mainly of fibrous tissue with a few haphazardly interspersed small follicles. The pericardial sac contained $50 \mathrm{ml}$ of clear straw col-

Table 2 Echocardiographic measurements ( $M$ mode)

\begin{tabular}{|c|c|c|c|c|}
\hline & \multirow[t]{2}{*}{ Case 1} & \multicolumn{3}{|l|}{ Case 2} \\
\hline & & $\begin{array}{l}\text { Before } \\
\text { treatment }\end{array}$ & $\begin{array}{l}\text { After } 6 \text { months } \\
\text { of } L \text {-thyroxine }\end{array}$ & $\begin{array}{l}\text { After } 18 \text { months } \\
\text { of L-thyroxine }\end{array}$ \\
\hline $\begin{array}{l}\text { Heart rate (beats/min) } \\
\text { Interventricular septum (mm) } \\
\text { LVPW (mm) } \\
\text { Septal: LVPW } \\
\text { LVPEP (ms) } \\
\text { LVET (ms) } \\
\text { LVPEP/LVET } \\
\text { LVSF (\%) } \\
\text { VCF (circ/s) (mean (SE)) } \\
\text { Isovolumic contraction period } \\
\text { (mean (SD) (ms)) }\end{array}$ & $\begin{array}{l}130 \\
10 \\
(3-7) \\
5 \\
(2 \cdot 5-6 \cdot 5) \\
2 \cdot 0 \\
(<1 \cdot 3) \\
75 \\
(47-79) \\
205 \\
(171-257) \\
0 \cdot 36 \\
(0 \cdot 29-0 \cdot 39) \\
59 \\
(24-46) \\
2 \cdot 8 \\
(1 \cdot 34(0 \cdot 03)) \\
-\end{array}$ & $\begin{array}{l}88 \\
8 \\
(4-8) \\
5 \\
(3 \cdot 5-7 \cdot 5) \\
1 \cdot 6 \\
(<1 \cdot 3) \\
111 \\
(60-91) \\
240 \\
(231-318) \\
0 \cdot 46 \\
(0 \cdot 29-0 \cdot 39) \\
65 \\
(24-46) \\
2 \cdot 7 \\
(1 \cdot 34(0 \cdot 03)) \\
61 \\
(33(7))\end{array}$ & $\begin{array}{l}115 \\
6 \cdot 5 \\
(4-8) \\
5 \\
(3 \cdot 5-7 \cdot 5) \\
1 \cdot 3 \\
(<1 \cdot 3) \\
62 \\
(52-83) \\
228 \\
(191-278) \\
0 \cdot 27 \\
(0 \cdot 29-0 \cdot 39) \\
52 \\
(24-46) \\
2 \cdot 26 \\
(1 \cdot 34(0 \cdot 03)) \\
20 \\
(33(7))\end{array}$ & $\begin{array}{l}100 \\
5 \cdot 5 \\
(4-8) \\
5 \\
(3 \cdot 5-7 \cdot 5) \\
1 \cdot 1 \\
(<1 \cdot 3) \\
70 \\
(56-87) \\
260 \\
(211-298) \\
0 \cdot 27 \\
(0 \cdot 29-0 \cdot 39) \\
35 \\
(24-46) \\
1.35 \\
(1 \cdot 35(0 \cdot 03)) \\
25 \\
(33(7))\end{array}$ \\
\hline
\end{tabular}

LVWP, left ventricular posterior wall; LVPEP, left ventricular pre-ejection period; LVET, left ventricular ejection time; LVSF, left ventricular shortening fraction; VCF, velocity of circumferential fibre shortening.

Numbers in parentheses are normal values from Latson and Gutgesell, ${ }^{9}$ with the exception of VCF and isovolumic contraction period which are from Goldberg $e t$ al $^{10}$ and Meyer ${ }^{11}$ respectively. 


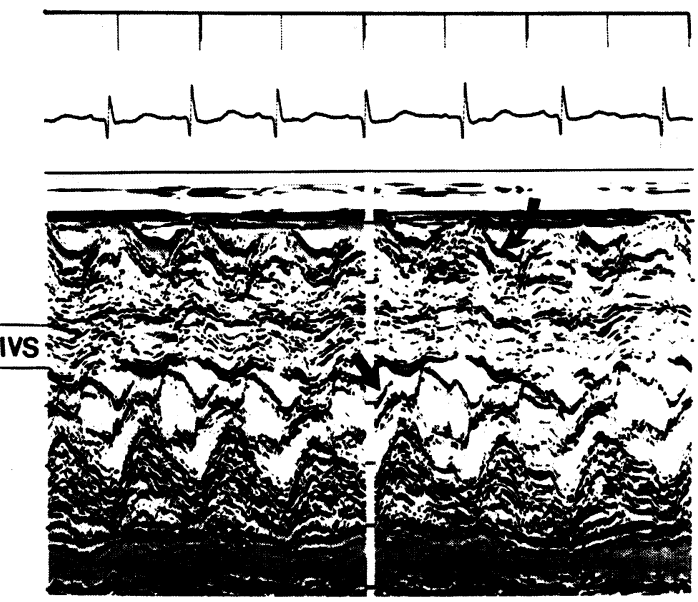

Fig. $1 M$ mode echocardiogram in case 1 showing pronounced thickening of the interventricular septum (IVS), systolic anterior motion of the mitral valve (straight arrow), and a pericardial effusion (curved arrow).

oured fluid. The heart weighed $66 \mathrm{~g}$ (normal (SD) 44 (8) g). This increase in weight was caused by gross asymmetric hypertrophy of the interventricular septum (thickness $10 \mathrm{~mm}$ ) which merged gradually with thickened left ventricular walls. The septal muscle bulged into the outflow tract of the left ventricle, and the ventricular cavity was small and distorted (Fig. 2). The papillary muscles were large with rounded tips. There was a band of endocardial thickening beneath the aortic valve. The right ventricular wall was only $2 \mathrm{~mm}$ thick. Elsewhere in the heart the endocardium was normal. The septum bulged slightly into the right ventricular outflow tract but the free wall of the right ventricle was not affected. The heart valves and coronary arteries were normal.

The microscopic abnormalities were most pronounced in the interventricular septum. The muscle fibres were moderately hypertrophied and there was focal interstitial fibrosis. There were occasional focal areas that showed shortening and abnormal interdigitations of the fibres (Fig. 3a). Thus there was evidence of slight muscle fibre disarray. There was, however, extensive vascuolation of the muscle fibres and there were foci of tissue in both anterior and posterior left ventricular walls showing this abnormality (Fig. 3b). The abnormal areas were mingled closely with areas of tissue with normal histological appearance. No inflammatory reaction was present and stains for mucopolysaccharides were negative.

CASE 2

A five year old girl was admitted to hospital because of short stature. She had a history of constipation. The child was pale and had been investigated for anaemia at 1 year of age. She weighed $13 \mathrm{~kg}$ and she was $88.5 \mathrm{~cm}$ tall (3rd percentile). Her heart rate was 82 beats per min. She had a sallow and dry skin and looked myxoedematous. There was hypertelorism and a flattened bridge to her nose. The thyroid gland was not palpable. The heart and chest were normal. Her abdomen protruded and she was very constipated. No visceromegaly was noted. Tendon reflexes were all present and equal but there was pronounced slowing of the recovery phase. Chest $x$ ray examination showed a heart of normal size and clear lung fields. The electrocardiogram showed a frontal QRS axis of $+150^{\circ}$; a positive "mosque" sign, and rather flattened ST-T wave segments. Thyroid function tests confirmed hypothyroidism (see Table 1). The serum cholesterol concentration was $12.03 \mathrm{mmol} / \mathrm{l}$ (normal 3.12-6.76 $\mathrm{mmol} / \mathrm{l}$ ) and microsomal antibodies 1:400. Bone age was 18 months on radio-

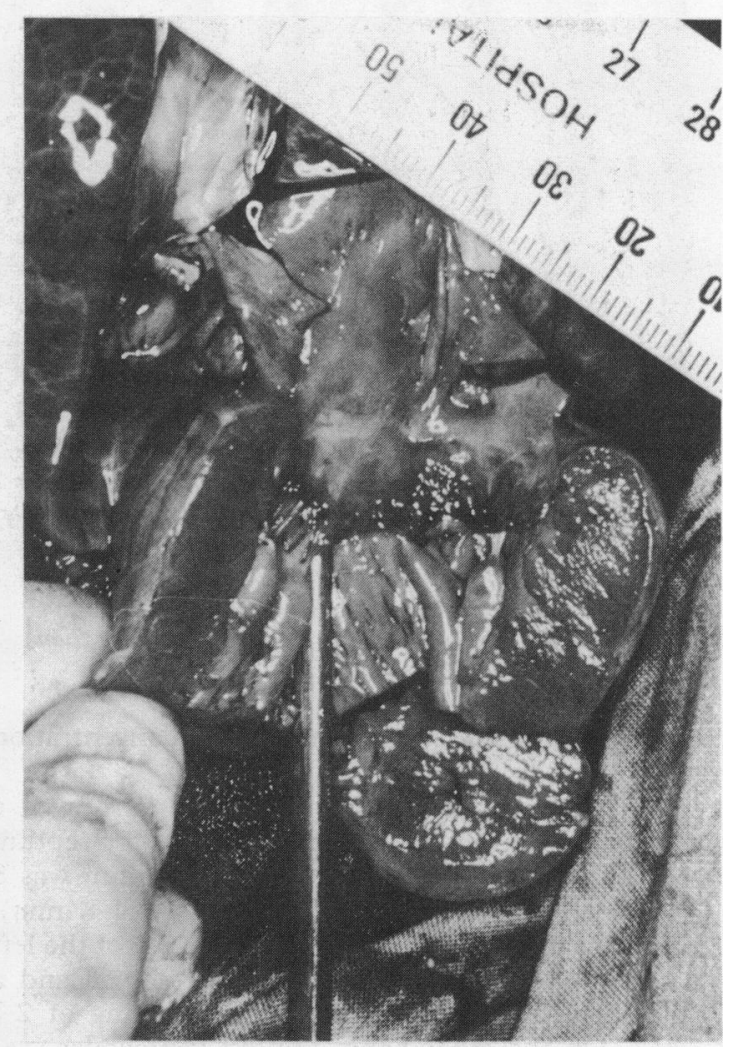

Fig. 2 Morphological appearance of left ventricle (opened) in case 1 showing pronounced hypertrophy of the interventricular septum and a thickened left ventricular wall. Probe is under the posterior leaflet of the mitral valve. Apex of the left ventricle has been cut in cross section. 


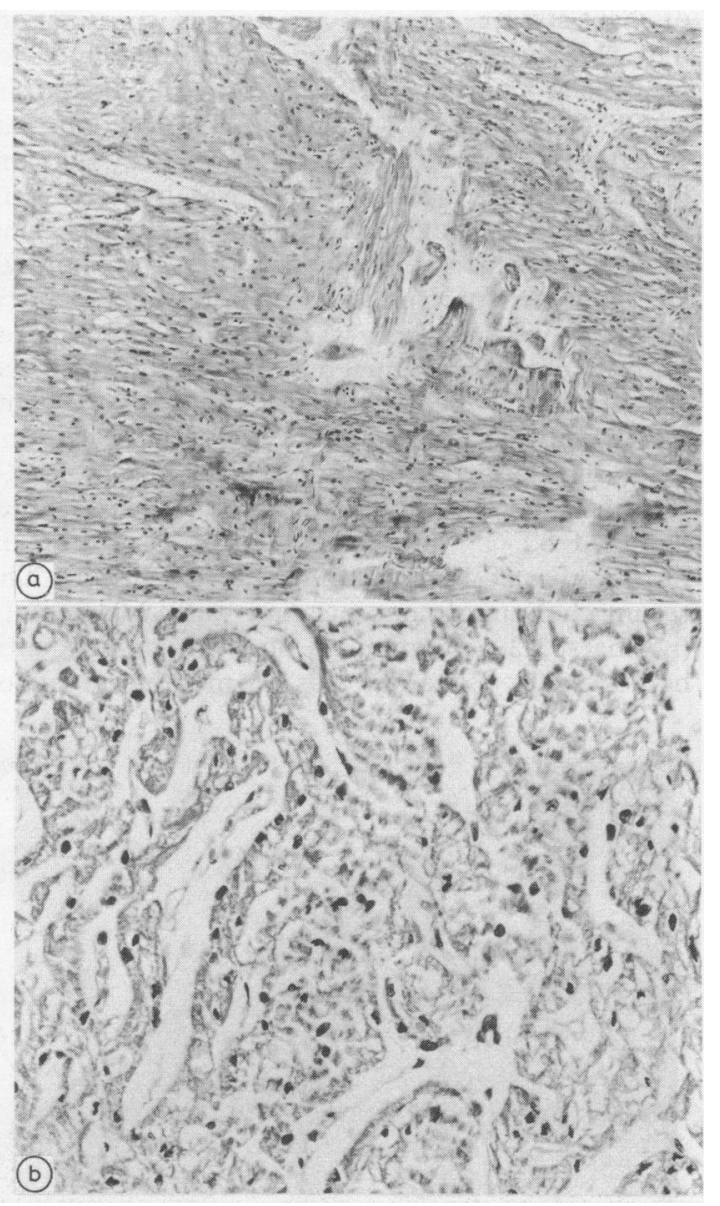

Fig. 3 Photomicrographs in case 1 of (a) interventricular septal myocardium showing abnormal arrangement of muscle fibres (haematoxylin and eosin $\times 132$ (original magnification). (b) Myocardium from interventricular septum showing extensive intracytoplasmic vacuolation. (Haematoxylin and eosin $\times 532$ ) (original magnification).

logical assessment. The haemoglobin concentration was $10 \cdot 4 \mathrm{~g} / \mathrm{dl}$.

An $M$ mode echocardiogram (Fig. 4) showed a disproportionately thickened septum with a septum to posterior wall ratio of $1 \cdot 6: 1$. The septum was 8 mm thick (normal mean $6 \mathrm{~mm}$; range 4-8 $\mathrm{mm}$ ). There was pronounced hypercontractility of the left ventricle with a shortening fraction of 0.65 and a velocity of circumferential fibre shortening of 2.7 $\mathrm{circ} / \mathrm{s}$. On the other hand, the left ventricular systolic time interval was prolonged-that is the ratio of the pre-ejection period to ejection time was increased..$^{-11}$ Cross sectional echocardiography confirmed the presence of asymmetric septal hyper- trophy. There was no systolic anterior motion of the mitral valve, no abnormalities of aortic valve motion, and no pericardial effusion.

Initially a dose of $0.05 \mathrm{mg} \mathrm{L}$-thyroxine was given, and this was later increased to $0 \cdot 1 \mathrm{mg}$ daily. Thyroid function had become normal three months after the start of treatment (Table 1).

A repeat echocardiogram after six months' treatment showed that the septal to posterior wall ratio had fallen to $1 \cdot 2: 1$ (to within normal limits) and the septal thickness was now within one standard deviation of the normal mean. There was still hyperdynamic ventricular contractility, however, with a shortening fraction of 0.52 and a velocity of circumferential fibre shortening of $2.26 \mathrm{circ} / \mathrm{s}$. These values and the left ventricular systolic time intervals became normal 18 months after the start of treatment (Table 2).

\section{Discussion}

The two cases we describe suggest that hypothyroidism may be associated with asymmetric septal hypertrophy. Until the recent report by Farooki et al we believed them to be the first cases to be described in children. ${ }^{6}$ Their two patients with asymmetric septal hypertrophy and hypothyroidism were much older than ours ( $81 / 2$ and 10 years). Our findings and theirs accord with those of Santos et al who reported similar features in adults. ${ }^{3}$ The fact that Hayford et al did not demonstrate cardiomyopathy in children may be related to the duration

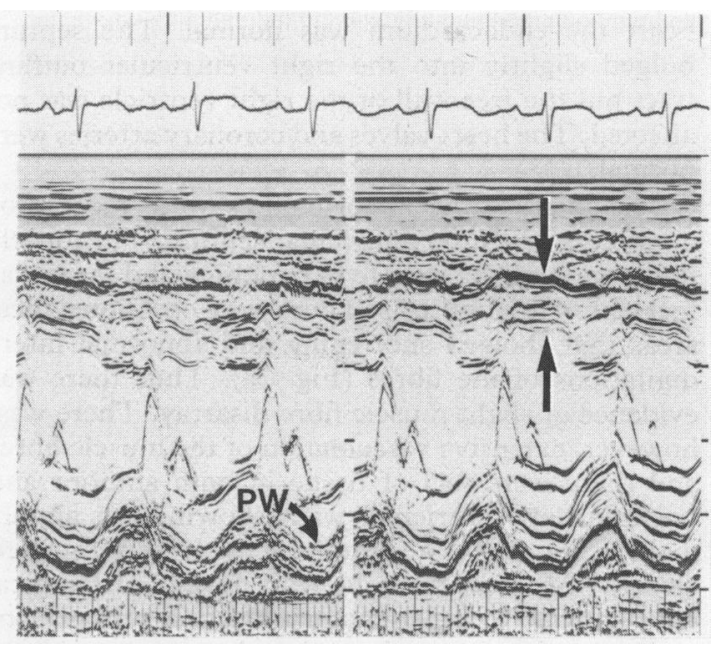

Fig $4 M$ mode echocardiogram in case 2 showing thickened interventricular septum (straight arrows) compared with the left ventricular posterior wall ( $P W)$. Mitral valve motion is normal. 
of the hypothyroidism before cardiac function was studied. ${ }^{4}$ Of their four cases with congenital hypothyroidism, three were less than 6 months of age, while the fourth was 1 year old. Our first case had clearly been hypothyroid from birth (11 months) and in the second case hypothyroidism may also have been present from, or shortly after, birth.

Another interesting echocardiographic finding in our surviving patient was that despite the rapid velocity of circumferential fibre shortening there was a prolonged left ventricular systolic time interval which shortened with thyroxine treatment. This accords with the reports of Nose et al and Farooki et al, who also noted prolonged left ventricular systolic time intervals in their hypothyroidic children that reversed with treatment. ${ }^{56}$

Pericardial effusion, which was present in the patient who died, is a recognised feature in hypothyroidism in both adults and children. ${ }^{146}$ But there were no specific microscopic changes warranting a diagnosis of myxoedematous heart disease. ${ }^{12}$ Vacuolation of muscle fibres, which was the most pronounced histological abnormality noted in our patient, has been reported in adults dying of hypothyroidism. ${ }^{12}$ The following microscopic abnormalities are generally considered to be those that are most typical of hypertrophic obstructive cardiomyopathy-short runs of fibres interrupted by connective tissue, large bizarre nuclei, fibrosis, degenerating muscle with disappearing myofibrils, and disorganised "whorling" muscle (muscle fibre disarray). ${ }^{1314}$ None of these abnormalities was readily seen in our first case. Thus it is unlikely that the asymmetric septal hypertrophy in this infant can be attributed to an intrinsic hypertrophic obstructive cardiomyopathy. Nevertheless, the findings of systolic anterior motion of the mitral valve on the echocardiogram and of a band of endocardial thickening beneath the aortic valve at necropsy provide evidence that the patient did indeed have dynamic subaortic stenosis. This might also explain the origin of the high pitched ejection systolic murmur in this child.

Both hyperthyroidism and hypothyroidism may result in asymmetric septal hypertrophy of the interventricular septum. In the early 1970 s three cases of hypertrophic cardiomyopathy and hyperthyroidism were described, ${ }^{15}$ and it was postulated that hyperthyroidism might act as a stimulus to produce excessive cardiac hypertrophy. Olsen et al administered triiodoacetic acid (Triac), a thyroxine analogue, to pregnant rats and induced electronmicroscopic changes typical of hypertrophic cardiomyopathy in the fetal but not in the maternal heart. ${ }^{16}$ The mechanism of action of Triac was not known. As result of these studies it was suggested that thyroid function should be assessed in patients with obscure forms of cardiac disease. Thyroid disease has been detected in $13 \%$ of 31 patients with hypertrophic obstructive cardiomyopathy.$^{17}$ Recently, in vitro experiments with triiodothyronine on isolated fetal mouse hearts in organ culture have been carried out. It was concluded that thyroid hormone directly stimulates cardiac protein synthesis and thus causes cardiac hypertrophy in the absence of major haemodynamic alterations. ${ }^{18}$

Paradoxically, Santos et al found asymmetric septal hypertrophy (by $M$ mode echocardiography) in 17 of 19 adult patients with untreated hypothyroidism. ${ }^{3}$ Some of the additional findings were similar to the echocardiographic features of idiopathic hypertrophic subaortic stenosis-for example, systolic anterior motion of the mitral valve. These abnormalities resolved in 10 patients when they became euthyroid on L-thyroxine treatment. The mechanism for the production of these changes is not known.

The findings in our two patients suggest that, as with adults, asymmetric septal hypertrophy can occur in some children with hypothyroidism, and that it may be reversible with treatment. Indeed, this is borne out by the recent report of Farooki et al who found asymmetric septal hypertrophy in two of 11 hypothyroid children. ${ }^{6}$ We therefore recommend that echocardiography should be carried out routinely in all babies and children with hypothyroidism, both before and during L-thyroxine replacement treatment.

\section{References}

1 Kerber RE, Sherman B. Echocardiographic evaluation of pericardial effusion in myxedema. Circulation 1975; 52: 823-7.

2 Crowley WF Jr, Ridgway EC, Bough EW, et al. Noninvasive evaluation of cardiac function in hypothyroidism: response to gradual thyroxine replacement. N Engl f Med 1977; 296: 1-6.

3 Santos AD, Miller RP, Mathew PK, Wallace WA, Cave WT Jr, Hinojosa L. Echocardiographic characterization of the reversible cardiomyopathy of hypothyroidism. Am F Med 1980; 68: 675-82.

4 Hayford JT, Schieken RM, Thompson RG. Cardiac function in primary hypothyroidism. Am $\mathcal{F}$ Dis Child 1980; 134: 556-9.

5 Nose O, Maki I, Harada T, Yabuuchi H. Systolic time interval in infants and children with primary hypothyroidism [Letter]. Am $\mathcal{F}$ Dis Child 1981; 135: 385.

6 Farooki ZQ, Hoffman WH, Perry BL, Green EW. Myocardial dysfunction in hypothyroid children. $\operatorname{Am} \mathcal{F}$ Dis Child 1983; 137: 65-8.

7 Fouron JC, Bourgin JH, Letarte J, Dussault JH, Ducharme G, Davignon A. Cardiac dimensions and myocardial function of infants with congenital hypothyroidism. An echocardiographic study. Br Heart $\mathcal{f}$ 
1982; 47: 584-7.

8 Ertugrul A. New electrocardiographic observation in infants and children with hypothyroidism. Pediatrics 1966; 37: 669-72.

9 Latson LA, Gutgesell HP. Pocket calculator program to compute normal values for echocardiographic measurements in children. Comput Biol Med 1981; 11: 161-5.

10 Goldberg SJ, Allen HD, Sahn DJ. Pediatric and adolescent echocardiography. Chicago: Year Book Medical Publishers, 1975: 65.

11 Meyer RA. Pediatric echocardiography. Philadelphia: Lea and Febiger, 1977: 278.

12 McKinney B. Pathology of the cardiomyopathies. London: Butterworth, 1974: 348.

13 Van Noorden S, Olsen EGJ, Pearse AGE. Hyper-

trophic obstructive cardiomyopathy, a histological, histochemical, and ultrastructural study of biopsy material. Cardiovasc Res 1971; 5: 118-31.

14 Olsen EGJ. The pathology of the heart. 2nd ed. London: Macmillan, 1980: 317-25.

15 Symons C, Richardson PJ, Feizi O. Hypertrophic cardiomyopathy and hyperthyroidism: a report of three cases. Thorax 1974; 29: 713-9.

16 Olsen EGJ, Symons C, Hawkey C. Effect of triac on the developing heart. Lancet 1977; ii: 221-3.

17 Bell R, Barber PV, Bray CL, Beton DC. Incidence of thyroid disease in cases of hypertrophic cardiomyopathy. Br Heart $\mathcal{F}$ 1978; 40: 1306-9.

18 Crie JS, Wakeland JR, Mayhew B, Wildenthal K. Direct anabolic effect of thyroid hormones on the heart [Abstract]. Circulation 1981; 64 (suppl IV): 277. 